\title{
The variant course of the suprascapular artery
}

\author{
N. Naidoo, L. Lazarus, B.Z. De Gama, K.S. Satyapal \\ Department of Clinical Anatomy, School of Laboratory Medicine and Medical Sciences, College of Health Sciences, \\ University of KwaZulu-Natal, Durban, South Africa
}

[Received 2 October 2013; Accepted 5 November 2013]

The suprascapular artery (SSA) has been identified to be of clinical relevance in surgical intervention and fracture healing of the shoulder. Despite the classic description of its course and relation to the superior transverse scapular ligament, it is subject to much variation. The aims of this study were: (i) to describe the course of the SSA in relation to the superior transverse scapular ligament, (ii) to determine the prevalence of the course of the SSA in relation to the superior transverse scapular ligament, (iii) to determine the prevalence of the variant origin of the SSA in cases presenting with variant course of the latter, and (iv) to establish a difference in laterality and that between adults and foetuses. The course of the SSA was investigated through the macro- and microdissection of the antero- and postero-superior shoulder regions of 31 adult and 19 foetal cadaveric specimens ( $n=100)$. The SSA was observed to pass inferior to the superior transverse scapular ligament accompanied by the suprascapular nerve (20\%), which corroborated the findings of previous studies. Subsequently, this variant course of the SSA also appeared to present with the variant origin of it in many instances (13\%): from the $3^{\text {rd }}$ part of the subclavian artery (4\%), $1^{\text {st }}$ part of the axillary artery (2\%), $2^{\text {nd }}$ part of the axillary artery (5\%) and SSA (2\%). Injury to the SSA may cause more serious trauma than that of arteries which are isolated from the great vessels, therefore the recognition and knowledge of variation in the origin and course of the SSA is significant in the treatment of diseases in the shoulder and cervical regions. Furthermore, the accompaniment of the suprascapular nerve with the SSA at the suprascapular notch inferior to the superior transverse scapular ligament may lead to neuropathy syndromes due to the pulsation of the artery against the nerve within the confined notch. (Folia Morphol 2014; 73, 2: 206-209)

Key words: suprascapular artery, variant, course, superior transverse scapular ligament

\section{INTRODUCTION}

The suprascapular artery (SSA) has been reported to generally arise from the thyrocervical trunk (i.e. a branch of the $1^{\text {st }}$ part of the subclavian artery) [9]. During its ascent to the superior margin of the scapula, the SSA provides muscular branches to the subscapularis, ster- nocleidomastoid and subclavius muscles, as well as the cutaneous suprasternal branch to the skin of the superior aspect of the thorax [11]. Upon reaching the superior scapular margin, it provides an acromial branch, which supplies the skin of the postero-superior shoulder [10]. The SSA then enters the supraspinous fossa on the dorsal

Address for correspondence: Prof. K.S. Satyapal, Department of Clinical Anatomy, School of Laboratory Medicine and Medical Sciences, College of Health Sciences, University of KwaZulu-Natal, Private Bag X54001, Durban 4000, South Africa, tel: + $27312607110 ;+27837778780$, fax: + 2731260 7890, e-mail: satyapalk@ukzn.ac.za 
Table 1. The course of the suprascapular artery in relation to the superior transverse scapular ligament

\begin{tabular}{|c|c|c|c|c|c|c|}
\hline \multirow[t]{2}{*}{ Course } & \multicolumn{2}{|c|}{ Side } & \multirow[t]{2}{*}{$\mathbf{P}$} & \multicolumn{2}{|c|}{ Individual subset } & \multirow[t]{2}{*}{$\mathbf{P}$} \\
\hline & Right & Left & & Foetal & Adult & \\
\hline Superior & 42 & 38 & \multirow{2}{*}{0.317} & 31 & 49 & \multirow{2}{*}{0.757} \\
\hline Inferior & 8 & 12 & & 7 & 13 & \\
\hline
\end{tabular}

aspect of the scapula superior to the superior transverse scapular ligament to supply the supraspinatus muscle [6].

However, the aforementioned characteristic passage of the SSA in relation to the superior transverse scapular ligament has not always been observed. The rare occurrence of the SSA passing inferior to the superior transverse scapular ligament (accompanied by the suprascapular nerve) has been documented in many studies [1, 2, 7, 8, 12-14]. According to Mishra and Ajmani [7] and Pyrgakis et al. [8], the cases which presented with a variant course of the SSA were also accompanied by the variant origin of it from the $1^{\text {st }}$ part of the axillary artery and the $3^{\text {rd }}$ part of the subclavian artery, respectively.

The aims of this study were: (i) to describe the course of the SSA in relation to the superior transverse scapular ligament, (ii) to determine the prevalence of the course of the SSA in relation to the superior transverse scapular ligament, (iii) to determine the prevalence of the variant origin of the SSA in cases presenting with the variant course of the latter, and (iv) to establish a difference in laterality and that between adults and foetuses.

\section{MATERIALS AND METHODS}

This study was performed bilaterally on the axillary and scapular regions of 31 adult and 19 foetal cadaveric specimens. It was conducted in accordance with Chapter 8 of the National Health Act No. 61 of 2003 at the Department of Clinical Anatomy, University of KwaZulu-Natal, Durban, South Africa. Ethical clearance was obtained from the relevant institutional authority (Ethical Clearance Approval Number: LMMSEC 003/12). The origin and course of the SSA in all cadaveric specimens were examined through anterior and posterior approaches. Microdissection of the foetal cadaveric specimens was employed through the use of a micro dissector and a microscope (Stemi DV4 by Carl Zeiss AG, Germany).

\section{Statistical analysis}

The statistical analysis involved the comparisons of laterality and that of adult and foetal subsets. It

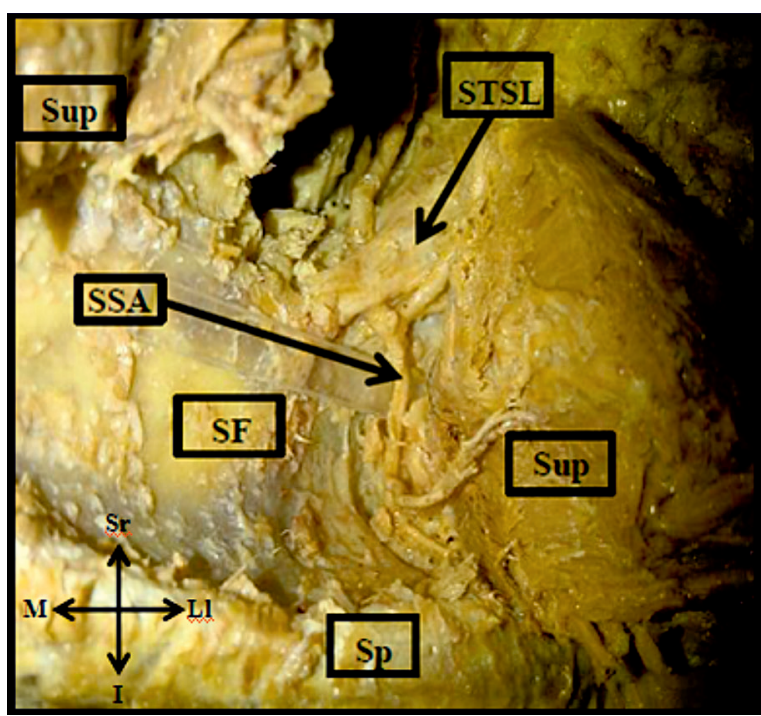

Figure 1. Suprascapular artery passing inferior to the superior transverse scapular ligament; I — inferior; LI — lateral; M — medial; $\mathrm{Sr}$ - superior; SF — supraspinous fossa; Sp — spine of scapula; SSA — suprascapular artery; Sup — supraspinatus muscle; STSL - superior transverse scapular ligament.

was performed using SPSS version 19.0 (SPSS Inc., Chicago, Illinois, USA). A p value of $<0.05$ was considered to be statistically significant.

\section{RESULTS}

The SSA was observed to pass over the superior transverse scapular ligament in $80 \%$ of the specimens ( $n=80 / 100$; right 42/50; left 38/50) (Table 1).

In $20 \%$ of the specimens ( $n=20 / 100$, right $8 / 50$; left 12/50), the SSA passed inferior to the superior transverse scapular ligament accompanied by the suprascapular nerve (Fig. 1, Table 1). Subsequently, in the cases presenting with the variant course of the SSA, the classical origin of the SSA from the thyrocervical trunk was recorded in $7 \%$ of the specimens ( $n=7 / 100$, right 2/50; left 5/50). The remaining $13 \%$ of the specimens ( $n=13 / 100$, right $5 / 50$; left $8 / 50$ ) harboured variant origins of the SSA: from the $3^{\text {rd }}$ part of the subclavian artery in $4 \%$ of the specimens 


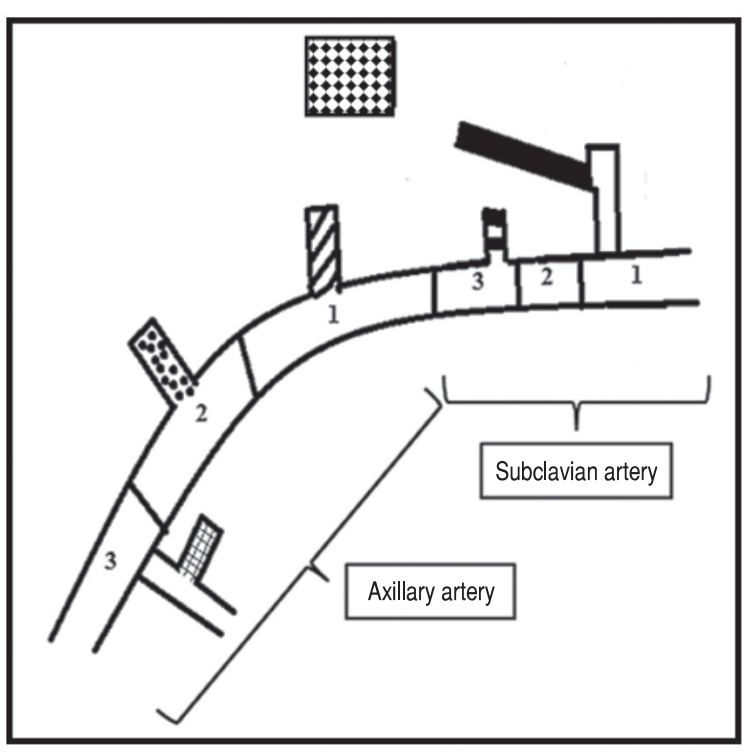

Suprascapular notch

Suprascapular artery arising from thyrocervical trunk

Suprascapular artery arising from $3^{\text {rd }}$ part of subclavian artery

Suprascapular artery arising from $11^{\text {st }}$ part of axillary artery

Suprascapular artery arising from $2^{\text {nd }}$ part of axillary artery

田

Suprascapular artery arising from subscapular artery

Figure 2. Schematic diagram of the variant course of the suprascapular artery including its origin.
( $n=4 / 100$, right $2 / 50$; left $2 / 50$ ), the $1^{\text {st }}$ part of axillary artery in $2 \%$ of the specimens $(n=2 / 100$, right $1 / 50$; left $1 / 50)$, the $2^{\text {nd }}$ part of axillary artery in $5 \%$ of the specimens ( $n=5 / 100$, right $4 / 50$; left $1 / 50)$ and the subscapular artery in $2 \%$ of the specimens ( $n=2 / 100$, right 1/50; left 1/50) (Fig. 2, Table 2).

There were no statistically significant differences between the sides nor was there a difference between foetal and adult subsets.

\section{DISCUSSION}

The variant course of the SSA inferior to the superior transverse scapular ligament, which was observed in $20 \%$ of the specimens of the present study, has been reported by many authors and compared significantly with a weighted mean of 4.26 (Table 3) $[1,2,7,8,12-14]$. This unusual occurrence of the SSA has been implicated to result in suprascapular entrapment neuropathy due to compression of the suprascapular nerve [1,4].

Furthermore, Mishra and Ajmani [7] and Pyrgakis et al. [8] identified that the variant course of the SSA was accompanied by a variation of its origin. This was confirmed in $13 \%$ of the specimens of the current study which compared favourably with a weighted mean of 1.67 (Table 4). The origin of the SSA and its course in relation to the superior transverse scapular

Table 2. The origin of the suprascapular artery in relation to its unusual course

\begin{tabular}{|c|c|c|c|c|c|c|c|}
\hline \multirow[t]{2}{*}{ Origin } & & \multicolumn{2}{|c|}{ Side } & \multirow[t]{2}{*}{$\mathbf{P}$} & \multicolumn{2}{|c|}{ Individual subset } & \multirow[t]{2}{*}{$\mathbf{P}$} \\
\hline & & Right & Left & & Foetal & Adult & \\
\hline Normal & Thyrocervical trunk & 2 & 5 & \multirow{5}{*}{0.544} & 0 & 7 & \multirow{5}{*}{0.229} \\
\hline \multirow[t]{4}{*}{ Variation } & $3^{\text {rd }}$ part of subclavian artery & 2 & 2 & & 2 & 2 & \\
\hline & $1^{\text {st }}$ part of axillary artery & 1 & 1 & & 1 & 1 & \\
\hline & $2^{\text {nd }}$ part of axillary artery & 4 & 1 & & 1 & 4 & \\
\hline & Subscapular artery & 1 & 1 & & 0 & 2 & \\
\hline
\end{tabular}

Table 3. Weighted mean of the variant course of the suprascapular artery inferior to the superior transverse scapular ligament

\begin{tabular}{lcc}
\hline Author (year) & Sample size & Incidence (\%) \\
\hline Mishra and Ajmani (2003) [7] & 60 & 1.7 \\
Tubbs et al. (2003) [13] & 120 & 2.5 \\
Adibatti and Prasanna (2010) [1] & 60 & 1.7 \\
Yang et al. (2012) [14] & 103 & 10.9 \\
Pyrgakis et al. (2013) [8] & 62 & 1.6 \\
Weighted mean & & $\mathbf{4}$ \\
Current study & 100 & 20 \\
\hline
\end{tabular}


Table 4. Weighted mean of the variant origin of the suprascapular artery in relation to its variant course

\begin{tabular}{lccccc}
\hline Author (year) & Sample size & \multicolumn{4}{c}{ Incidence (\%) } \\
\cline { 3 - 6 } & & $\begin{array}{c}3^{\text {rd }} \text { part of } \\
\text { subclavian } \\
\text { artery }\end{array}$ & $\begin{array}{c}1^{\text {st }} \text { part of } \\
\text { axillary } \\
\text { artery }\end{array}$ & $\begin{array}{c}2^{\text {nd }} \text { part of } \\
\text { axillary } \\
\text { artery }\end{array}$ & $\begin{array}{c}\text { Subscapular } \\
\text { artery }\end{array}$ \\
\hline Mishra and Ajmani (2003) [7] & & - & 1.7 & - & - \\
Adibatti and Prasanna (2010) [1] & 60 & - & 1.7 & - & - \\
Pyrgakis et al. (2013) [8] & 60 & 1.6 & - & - & - \\
Weighted mean & 62 & & 1.67 & 5 & 2 \\
Current study & & 4 & 2 & 5 \\
\hline
\end{tabular}

ligament has been identified to be of clinical significance [8]. Although the classical origin of the SSA from the thyrocervical trunk is characterised by a lengthier SSA, it is considered to reduce the risk of injury to the artery (Fig. 2) [8]. Moreover, radical and modified surgeries require the ligation of this longer SSA to control the spread of lymphoma in the neck [3]. The SSA presenting with a variation in origin has a different distance to travel to reach the superior transverse scapular ligament at the suprascapular notch (Fig. 2) [8]. This may subject the SSA to damage by clavicular fractures depending on the situation of the artery $[5,8]$.

\section{CONCLUSIONS}

This study presented a sizable degree of variation of the SSA course inferior to the superior transverse scapular ligament (20\%). Although variation in the course of the SSA is rare, several of these occurrences were accompanied by the variant origin of the artery as well (13\%). The observations and findings of this study corroborate those of previous studies. Clinical implications of these results may manifest as the impingement of the suprascapular nerve, compression of the SSA, wasting of the spinati muscles and severe shoulder weakness and discomfort.

\section{REFERENCES}

1. Adibatti M, Prasanna LC (2010) Variation in origin of suprascapular artery. Int J Anat Variations, 3: 178-179.
2. Alashkham A, Alraddadi A, Soames R (2013) Variation of the suprascapular artery. AXIS, 4: 1-7.

3. Atsas S, Fox JN, Lambert HW (2011) The rare origin of the suprascapular artery arising of the internal thoracic artery in the presence of the thyrocervical trunk: clinical and surgical implications. Int J Anat Variations, 4: 182-184.

4. Clein $\sqcup$ (1975) Suprascapular entrapment neuropathy. J Neurosurg, 43: 337-342.

5. Kato K (1989) Innervation of the scapular muscles and its morphological significance in man. Anat Anz, 168: 155-168.

6. Ling SC, Chen CF, Wan RX (1990) A study on the vascular supply of the supraspinatus tendon. Surg Radiol Anat, 12: 161-165.

7. Mishra S, Ajmani ML (2003) Anomalous origin of suprascapular artery. J Anat Soc India, 52: 180-182.

8. Pyrgakis P, Panagouli E, Venieratos D (2013) Anomalous origin and course of the suprascapular artery combined with absence of the suprascapular vein: case study and clinical implications. N Am J Med Sci, 5: 129-133.

9. Sinnatamby CS (2006) Last's anatomy: regional and applied. Churchill Livingstone, New York, pp. 444-463.

10. Standring S (2009) Gray's anatomy: the anatomical basis of clinical practice. Elsevier Ltd, Spain, pp. 830-845.

11. Tobias PV, Arnold M (1977) Man's anatomy: back and limbs. Witwatersrand University Press, South Africa, pp. 90-108.

12. Tubbs RS, Shoja MM, Shokouhi G, Loukas M, Oakes WJ (2007) Retrosplenic course of the transverse cervical artery with the suprascapular artery travelling through the suprascapular notch. Folia Morphol, 66: 80-82.

13. Tubbs RS, Smyth MD, Salter G, Oakes WJ (2003) Anomalous traversement of the suprascapular notch: a possible mechanism for undiagnosed shoulder pain. Med Sci Monit, 9: 116-119.

14. Yang HJ, Gil YC, Jin JD, Ahn SV, Lee HY (2012) Topographical anatomy of the suprascapular nerve and vessels at the suprascapular notch. Clin Anat, 25: 359-365. 